\title{
Role of gravitational cues in the haptic perception of orientation
}

\author{
EDOUARD GENTAZ and YVETTE HATWELL \\ Université Pierre Mendès France, Grenoble, France
}

\begin{abstract}
The haptic perception of vertical, horizontal, $+45^{\circ}$-oblique, and $+135^{\circ}$-oblique orientations was studied in adults. The purpose was to establish whether the gravitational cues provided by the scanning arm-hand system were involved in the haptic oblique effect (lower performances in oblique orientations than in vertical-horizontal ones) and more generally in the haptic coding of orientation. The magnitude of these cues was manipulated by changing gravity constraints, and their variability was manipulated by changing the planes in which the task was performed (horizontal, frontal, and sagittal). In Experiment 1, only the horizontal plane was tested, either with the forearm resting on the disk supporting the rod ("supported forearm" condition) or with the forearm unsupported in the air. In the latter case, antigravitational forces were elicited during scanning. The oblique effect was present in the "unsupported" condition and was absent in the "supported" condition. In Experiment 2 , the three planes were tested, either in a "natural" or in a "lightened forearm" condition in which the gravitational cues were reduced by lightening the subject's forearm. The magnitude of the oblique effect was lower in the "lightened" condition than in the "natural" one, and there was no plane effect. In Experiment 3, the subject's forearm was loaded with either a 500- or a 1,000-g bracelet, or it was not loaded. The oblique effect was the same in the three conditions, and the plane effect (lower performances in the horizontal plane than in the frontal and sagittal ones) was present only when the forearm was loaded. Taken together, these results suggested that gravitational cues may play a role in haptic coding of orientation, although the effects of decreasing or increasing these cues are not symmetrical.
\end{abstract}

The problem studied here is how humans perceive vertical, horizontal, and oblique orientations in the haptic (tactual-kinesthetic) modality. In vision, performance on a variety of perceptual tasks is superior for stimuli arranged in the vertical and horizontal orientations as opposed to oblique orientations. The origin of this anisotropy, called the "oblique effect" by Appelle (1972), is still unclear. Essock (1980) proposed a distinction between "class 1 oblique effects," observed when one is measuring the basic functioning of the visual system (acuity, contrast threshold, and other measures of sensitivity) and "class 2 oblique effects," reflecting memory, learning, perceptual, and cognitive processes. Class 1 effects are consistently explained by physiological factors, such as anisotropy in the population of cortical cells (Dick \& Hochstein, 1989; Essock, 1980, 1982, 1990; Heeley \& Timmey, 1988; Jenkins, 1985; Long \& Tuck, 1991; Saarinen \& Levi, 1995). The origin of Class 2 oblique effects is less clear and has been attributed to different factors:

This work was supported by grants from the Universite Pierre Mendès France of Grenoble and from the Centre National de la Recherche Scientifique (ER 0085). We thank Christian Marendaz and Théophile Ohlmann for their suggestions, and also Lester Krueger, Thomas Fikes, and two anonymous reviewers for their helpful comments on an earlier version of this manuscript. Correspondence and requests for reprints should be sent to E. Gentaz or Y. Hatwell, Laboratoire de Psychologie Expérimentale, Université Pierre Mendès France, BP 47, 38040 Grenoble Cedex 9, France (e-mail: gentaz@, ccomm.grenet.fr). left-right discrimination (Corballis \& Beale, 1976), memory deficit (Bryant, 1974; Harris, Le Tendre, \& Bishop, 1974), or selective practice (Vogels \& Orban, 1985).

These Class 2 oblique effects may also be affected by the reference frame used, because obliques are obliques only through reference to some spatial frame. The presence of an oblique effect therefore reveals a spatial coding relative to a frame. According to Rock (1983, p. 332), reference frames have "the status of principles of organization." The classical distinction between egocentric (with reference to the subject's body) and allocentric (with reference to external cues) frames is considered today to be too restrictive. Paillard (1991; see Berthoz, 1991) proposed that both egocentric and allocentric frames depend on a geocentric frame based on the direction of gravity and defining a Cartesian coordinate system with vertical and horizontal coordinate axes. In the frontal plane, coding of the vertical and horizontal orientations requires one to process one of the coordinate axes only, whereas oblique orientations require a coding taking into account both axes (Cecala \& Garner, 1986; Lasaga \& Garner, 1983) and integrating the parameters computed on each one. The difference between these two modes of coding would contribute largely to the oblique effect.

These analyses are not specific to visual perceptions and may be extended to haptic ones. To support this view, Cecala and Garner (1986) showed that adults localize a point visually by using an internal (not modality-specific) set of references aligned with the vertical and horizontal 
directions given by gravity. On the other hand, Soechting and Ross (1984) and Worringham, Stelmach, and Martin (1987) reported that the proprioceptive signals are perceived more readily in terms of limb segment inclination in relation to the gravitational vertical than as joint angles.

This reference to gravity may be enhanced in haptic as opposed to visual perception because, when the armhand system scans an oriented rod, it develops antigravitational forces that provide gravitational cues to the subject. Gravitational cues are indirect cues taken from the proprioceptive information contained in the pattern of tissue deformations (skin mechanoreceptors, joints, and muscles). These deformations depend on the specific muscular forces necessary to maintain and move the armhand system under the gravity environment $(\mathrm{G})$ during perceptual exploration. Recent data show that muscle receptors contribute significantly to the proprioceptive limb sense (for a review, see Roll; 1994). For example, when a stationary limb is made to vibrate, subjects experience consistent illusory limb movements (Goodwin, McCloskey, \& Matthews, 1972; Roll, Vedel, Gilhodes, \& Ribot, 1986). Since muscle receptors are sensitive to the action of external forces on the limb, they are likely to be affected by changed gravity (Bock, 1994).

Researchers examining the effects of $G$ level (simulated or actual) have been concerned mainly with arm movement control (Fisk, Lackner, \& Dizio, 1993) or position/movement proprioceptive sense (Bock, 1994). Very few have studied these effects on haptics (Marchetti \& Lederman, 1983). The results show that the accuracy of aimed arm movements deteriorates under changed gravity (Bock, Howard, Money, \& Arnold, 1992; Coello \& Orliaguet, 1994; Coello, Orliaguet, \& Prablanc, 1996; Watt et al., 1985). A proposed explanation is that proprioceptive information about arm position and movement was degraded under these conditions. Various physiological explanations have been proposed: some authors have suggested that the muscle spindle activity is modified in changed gravity, whereas others have assumed the existence of body graviceptors, which could be the Golgi tendon organs (Dietz, 1994).

In haptics, in addition to the level of $\mathrm{G}$, the gravitational and antigravitational forces at work during the arm-hand scanning depend on the plane in which the task is performed. The planes already studied in contemporary research are horizontal (like the surface of a table), frontal (like the surface of a blackboard on a wall), and sagittal (in the median plane passing through the midline of the subject's head). In the latter two planes, the movements exploring the stimulus rod in the bottomup direction require high muscular antigravitational forces, whereas those in the reverse direction need less muscular effort. Consequently, the magnitude of the gravitational cues is highly variable during scanning. By contrast, in the horizontal plane, this variability is minimal: because movements are performed in front of the subject in a direction perpendicular to gravity, they re- quire constant antigravitational forces. It may therefore be that, in addition to the level of $G$, the variability of gravitational cues affects the accuracy of haptic orientation coding.

Prior research on haptic perception of orientation rarely controlled the plane in which the task was performed, and Gentaz and Hatwell (1995) suggested that controlling this factor could clarify some results. For example, the oblique effect was found in blindfolded sighted adults tested haptically in the frontal plane by Lechelt, Eliuk, and Tanne (1976) and Lechelt and Verenka (1980), and it was found too in the passive touch of congenitally blind adults tested in the horizontal plane (Lechelt, 1988 , 1992). According to Lechelt, these results revealed the importance of experiential and learning factors: because verticals and horizontals are privileged in our "carpentered" environment, and because this factor acts similarly in vision and haptics, the same oblique effect is at work in the two modalities. But Appelle and Countryman (1986) questioned this interpretation. They argued that in blindfolded sighted subjects, the haptic oblique effect demonstrated by Lechelt et al. "was not related to haptic sensitivity, but stemmed ... from the inherently different scanning patterns required in bilateral exploration of obliques" (p. 325)-that is, when one hand explored the standard and, after a delay, the other hand set the response rod (as was the case in Lechelt's experiments). These movements activate the same pattern of agonist/antagonist muscles and tendons when the standard is vertical or horizontal, but they differ when it is oblique. Appelle and Countryman (1986) tested this assumption by comparing Lechelt's "twohands" procedure (but in the horizontal plane instead of the frontal plane) and another one in which the same hand explored the standard and then set the response rod ("one-hand" condition). In the latter case, the same scanning movements were at work for both the verticalhorizontal rods and the oblique ones. The results supported the authors' predictions: the oblique effect was present in the two-hand condition and absent in the onehand condition.

But Appelle and Countryman's (1986) hypothesis was not supported by further observations obtained when the planes in which the task was performed were varied. Gentaz and Hatwell (1995) asked blindfolded subjects to perform the task in ipsilateral (one-hand) and controlateral (two-hand) conditions in the horizontal plane (as in Appelle \& Countryman's study), the frontal plane (as in Lechelt et al., 1976; Lechelt \& Verenka, 1980), or the sagittal plane. The interest in the sagittal plane stems from the fact that in it, the same pattern of agonist/antagonist muscles and tendons are activated when one is setting verticals, horizontals, and obliques. Nevertheless, the haptic oblique effect was present in this sagittal plane, even when the same hand explored and set the response rod. Consequently, the difference between scanning movements could not be considered as the main factor generating the haptic oblique effect. 
Two results reported by Gentaz and Hatwell (1995) needed further analysis, however. First, the accuracy of performances was globally higher in the frontal and sagittal planes (which did not differ) than in the horizontal plane. This observation will be referred to henceforth as the plane effect. Second, as in Appelle and Countryman's (1986) study, the oblique effect was absent in the horizontal plane when the subjects performed the task in the one-hand condition (labeled "ipsilateral" by Gentaz \& Hatwell, 1995), whereas it was present in the two-hand condition (labeled "controlateral" by Gentaz \& Hatwell, 1995).

The interpretation of Gentaz and Hatwell (1995) was that the haptic oblique effect depended in some ways on the magnitude and the variability of the gravitational cues provided by the arm-hand system when it acted in space. Contrary to finger movements, shoulder and arm movements are constrained by the gravity environment (Martinez, 1971; Paillard, 1971, 1974, 1991) and by the plane in which the movement is performed (Fisk et al., 1993; Robert \& Ohlmann, 1994; Wong, 1977). In the haptic task used by Gentaz and Hatwell (1995), the length of the rod was $25 \mathrm{~cm}$, and therefore the arm and shoulder were involved in scanning. Although the magnitudes of the available gravitational cues were similar in the three planes (normal G level), their variability was different according to the plane, as has been discussed earlier.

These differences may explain why the oblique effect was not present in the ipsilateral-horizontal condition of Gentaz and Hatwell's study (1995). In the horizontal presentation of their display, the stimulus rod was fixed in direct contact with a metal disk and could rotate around its center. When scanning the rod, the subject's wrist and forearm could partly rest on the disk surface, which acted as a support. Consequently, reduced muscular antigravitational forces were needed in order to maintain the arm at the level of the stimulus, and, as a result, the gravitational cues provided by the scanning arm-hand system were decreased. If coding relied on a Euclidean spatial reference frame, decreasing information on the gravitational vertical would affect the accuracy of responses in all orientations, since all of them refer to the gravitational vertical. However, under decreased gravity cues, coding the vertical (and correlatively the horizontal) orientation may be more impaired than coding obliques, because, although it remains a coordinate axis, the vertical orientation loses the benefit of being directly specified by the gravity cues elicited during haptic scanning. As a result, no oblique effect would appear in this condition.

In sum, we assumed that the haptic perception of orientation might be influenced by the magnitude and the variability of the gravitational cues elicited by the scanning arm-hand system. As a result, we predicted that (1) the oblique effect would be observed in the presence of gravitational cues (natural cues or enhanced cues), because these cues help the coding of the vertical and horizontal orientations more than the oblique ones; this oblique effect would be absent or reduced when the magnitude of gravitational cues was lowered: and (2) what- ever the mean magnitude of these cues, the level of variability of the gravitational cues during scanning would affect the global accuracy of haptic orientation coding. High variability of cues would enhance, whereas low variability would impair, performance. As a result, fewer errors would be observed in the frontal and sagittal planes than in the horizontal one (the plane effect).

In the present study, we tested these hypotheses. The magnitude of gravitational cues was manipulated by simulating changes in environmental gravity. The level of variability of these cues was modified by performing the task in the three planes: horizontal, frontal, and sagittal.

In Experiment 1, we examined the first hypothesis only in the horizontal plane. In it, the distance between the stimulus rod and the disk was either $0 \mathrm{~cm}$ (in the supported-forearm condition, replicating the condition used by Gentaz \& Hatwell, 1995), or $8 \mathrm{~cm}$. In the latter unsupported-forearm condition, the subject's forearm could no longer rest in physical contact with the disk surface during scanning and was actively maintained in the air by the subject. If the magnitude of gravitational cues was responsible for the elicitation of the oblique effect, this effect would be present in the unsupported-forearm condition (where the magnitude of gravitational cues was "natural") and would be reduced or absent in the "supported forearm" condition (where this magnitude was lowered).

In Experiments 2 and 3, we studied further the role of gravitational cues. In Experiment 2, we reduced the magnitude of these cues by lightening the subject's forearm with a device in which the exploring forearm was connected with a weight sliding along two pulleys. In Experiment 3, we enhanced the magnitude of gravitational cues by loading the subject's forearm with a bracelet weighing 500 or $1,000 \mathrm{~g}$. These two experiments were performed in the three planes: horizontal, frontal, and sagittal. If the magnitude and the variability of gravitational cues were involved in the haptic coding of orientation, the oblique effect and the plane effect would be reduced or absent in the lightening condition (Experiment 2 ) and would be enhanced in the loading condition (Experiment 3).

\section{EXPERIMENT 1}

In this experiment, subjects were asked to explore a standard orientation in the horizontal plane and then to reproduce this orientation ipsilaterally (i.e., with the same hand) in one of two conditions. Condition 1 (supported forearm) replicated the condition of exploration, proposed by Appelle and Countryman (1986) and Gentaz and Hatwell (1995), which revealed no oblique effect. In this condition, the stimulus rod was fixed directly on the disk surface and, therefore, the wrist and forearm could rest physically on it while the hand explored the rod. The magnitude of gravitational cues was minimal in this condition and stemmed only from the reaction force of the disk. In Condition 2 (unsupported forearm), the 
stimulus rod was $8 \mathrm{~cm}$ distant from the disk and, therefore, antigravitational forces should be elicited in order to explore the rod. Therefore, the magnitude of gravitational cues was higher in this condition than in Condition 1. If gravitational cues participated in the haptic oblique effect, an oblique effect should be observed under the unsupported-forearm condition and should be reduced or absent in the supported-forearm condition.

\section{Method}

Subjects. The subjects were 24 right-handed undergraduate students in psychology and sociology ( 12 males, 12 females), who participated in the experiment in exchange for extra course credit. Their handedness was assessed with the use of Bryden's five-item (1977) hand preference questionnaire (writing, throwing, drawing, scissors, and toothbrush).

Apparatus. The apparatus was composed of a black metal disk (diameter, $40 \mathrm{~cm}$ ) equipped with a rod $(25 \times 1.8 \mathrm{~cm})$. This rod, mounted on the center of the disk, could be rotated $360^{\circ}$ around its central axis. Magnets were fixed inside the rod to maintain it in the desired orientation and to prevent involuntary deviation from its position during haptic scanning. A small amount of force was required for its position to be changed intentionally. This rod could be fixed either directly in contact with the disk (in Condition 1), or parallel to the disk surface at $8 \mathrm{~cm}$ from it (in Condition 2; see Figure 1). The force required to change the position of the rod was similar in the two conditions. The rod was connected to a potentiometer, which indicated (in degrees) to what extent its orientation deviated from the vertical. This vertical orientation was arbitrary defined as aligned with the subject's midsagittal plane. The disk was positioned in the horizontal plane (like the surface of a table) and was centered on the subject's body midline. The subjects sat in the front midline of the apparatus, perpendicular to the surface of the disk. and were asked to maintain their trunk fixed upright. The height of the disk was adjusted with reference to the subject's height, so that the rod was positioned at a level under the subject's chest.

Experimental conditions and Procedure. The subject was taken individually into a quiet room in which the apparatus was masked by a cloth, and was then blindfolded with translucent glasses that passed light but no pattern information. The task was to scan haptically with one hand (i.e., to move actively the armhand-digit system) on the oriented standard rod and to reproduce the same orientation with the same hand after a 5-sec delay. A 5-sec delay was introduced to replicate Appelle and Countryman's (1986) and Gentaz and Hatwell's (1995) procedures. Because the same rod was alternatively the standard and response rod, this delay was also used by the experimenter to modify the orientation of the rod between the presentation and the response phases. The initial orientation of the response rod was never one of the four tested orientations. It was approximately $80^{\circ}$ more or less than the standard orientation tested during the trial and was determined at random by the experimenter at the right or the left of the standard orientation. During the delay, the subject was asked to move his/her hand off the display and to maintain it in contact with his/her abdomen.

The subjects explored haptically the standard with one hand over its full length. After the delay, using the same hand, they set the response rod. Each subject was tested under one of two exploratory conditions. In the first, or supported-forearm, condition, the rod was in direct contact with the disk surface. The subject was instructed to maintain his/her wrist and forearm resting in physical contact with the disk support during the whole trial. In a familiarization phase, the arm--hand system was first guided by the experimenter and the subject was trained to explore actively under these instructions. In the second, or unsupported-forearm, condition, the subjects explored a rod $8 \mathrm{~cm}$ distant from the disk

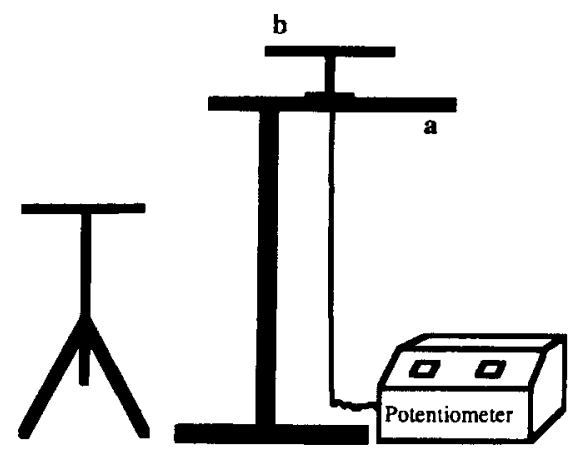

A

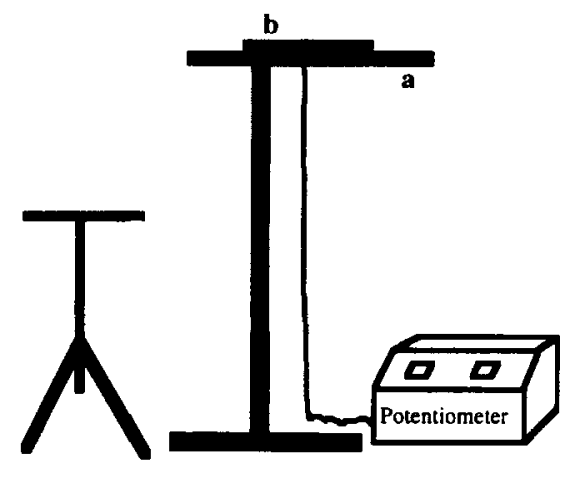

B

Figure 1. Lateral view of the apparatus, with the disk positioned in the horizontal plane and the rod fixed either directly in contact with the disk (B), or $8 \mathrm{~cm}$ distant from the disk (A): Experiment 1 . a, disk; b, stimulus rod.

surface and parallel to it. For each exploration condition, half the subjects used the right hand and the other half used the left.

Four orientations were tested in the horizontal plane: $0^{\circ}$ (vertical), $45^{\circ}$ (left-slanting oblique in relation to subject's view), $90^{\circ}$ (horizontal, perpendicular to the subject's sagittal plane), and $135^{\circ}$ (right-slanting oblique in relation to subject's view). Three additional "catch" (distractor) trials in other orientations (randomly selected from among the following: $+15^{\circ},+75^{\circ},+105^{\circ}$, or $+165^{\circ}$ ) were interspersed with test trials in order to avoid inducing any awareness that the tested orientations were restricted to four. No feedback was given to the subject during the experiment and there was no time constraint.

Since each subject performed 3 trials in each of the 4 orientations tested, there were 12 test trials per subject. In addition, as stated earlier, 3 catch trials were presented randomly (i.e., 15 trials per subject).

\section{Results}

The data analyses were carried out on the angular difference (in degrees) between the positions of the standard and test rods. The mean error (signed and absolute) was then calculated for each of the four orientations for each subject.

The mean signed errors for each condition are shown in Table $1 \mathrm{~A}$. We considered that the four orientations 
Table 1A

Mean Signed Angular Errors, With Standard Deviations, as a Function of Forearm Condition and Stimulus Orientation in Experiment 1

\begin{tabular}{|c|c|c|c|c|c|c|c|c|}
\hline \multirow[b]{3}{*}{ Forearm } & \multicolumn{8}{|c|}{ Orientation } \\
\hline & \multicolumn{2}{|c|}{ Vertical } & \multicolumn{2}{|c|}{$+45^{\circ}$} & \multicolumn{2}{|c|}{ Horizontal } & \multicolumn{2}{|c|}{$+135^{\circ}$} \\
\hline & $M$ & $S D$ & $M$ & $S D$ & $M$ & $S D$ & $M$ & $S D$ \\
\hline Unsupported & $0.5^{\circ}$ & $2.5^{\circ}$ & $0.9^{\circ}$ & $6.6^{\circ}$ & $2.4^{0 *}$ & $3.3^{\circ}$ & $-0.1^{\circ}$ & $3.8^{\circ}$ \\
\hline Supported & $2.1^{\circ}$ & $4.0^{\circ}$ & $0.2^{\circ}$ & $3.5^{\circ}$ & $1.4^{\circ}$ & $5.1^{\circ}$ & $2.4^{\circ \dagger}$ & $4.1^{\circ}$ \\
\hline
\end{tabular}

Note-Probabilities for $t$ tests are as follows: ${ }^{*} p<.05 . \quad{ }^{\dagger} .10>p>$ .05 .

moved counterclockwise across an imaginary circle (whose origin was the vertical orientation), and we attributed to the subject's response a positive sign if there was an overestimation (the response rod was positioned too far from the standard) and a negative sign if there was an underestimation (see Figure 5). A preliminary analysis of variance (ANOVA) of signed errors showed that gender and hand had no effect and did not interact with any other factor. Consequently, results were further collapsed across gender and hand. A 2 (forearm condition) $\times 4$ (orientation) ANOVA (with repeated measures on the last factor) on signed errors revealed no significant effect of orientation $[F(3,66)=0.39, p>.25]$ or of forearm condition $[F(1,22)=0.38, p>.25]$, nor an interaction between these two factors $[F(3,66)=0.93, p>$ $.25]$. Further $t$ tests compared the mean values of each condition to zero, in order to determine whether there were systematic directional errors. Results of these tests (Table 1A) showed that errors tended to be positive but, except for one of them, they failed to reach significance. When the eight conditions were collapsed, the global mean error was positive $(M=1.24, S D=4.23)$ and significant $[t(95)=2.88, p<.01]$. This suggests that people have a tendency to slightly overshoot when setting the rod. The reason for this tendency is not clear.

The mean absolute errors for each condition are shown in Table 1B. Because absolute errors have generally an asymmetrical distribution, a logarithmic transformation $[\log (x+1)]$ was carried out on each angular difference in order to fulfill the normality condition required for the ANOVA (Abdi, 1987). The Lilliefors test (Lilliefors, 1967) for normality showed that the difference between the normal and the empirical distribution of scores in degrees (before transformation) was significant $[L$ (calculated $)=0.113>L$ (critical) $=0.105, p<.01]$ whereas the difference between the normal and empirical scores in $\log$ after transformation was not [ $L$ (calculated) $=$ $0.076<L$ (critical)]. Table 1B gives the mean absolute errors before transformation (in degrees) and after their $\log$ transformation.

A preliminary ANOVA on absolute errors in log showed that gender and hand had no effect and did not interact with any other factor. Consequently, results were collapsed across gender and hand. A 2 (forearm condition) $\times 4$ (orientation) ANOVA (with repeated measures on the last factor) on absolute errors in log revealed a main effect of orientation $[F(3,66)=3, p<.05]$. Partial analyses showed no difference between the vertical $(M=0.64)$ and horizontal $(M=0.72)$ orientations $[F(1,22)=2.5, p=.11]$, nor between the $45^{\circ}(M=$ $0.77)$ and $135^{\circ}(M=0.78)$ obliques $[F(1,22)=0.02, p>$ $.25]$. As it is classically done in the literature, we collapsed on the one hand the vertical and horizontal orientations, and on the other hand the two oblique orientations. This allowed a preplanned measure of the oblique effect. This effect (i.e., the difference between the magnitudes of errors when setting vertical-horizontal and obliques) was significant $[F(1,66)=6.6, p<.025]$ : errors were higher in the oblique $(M=0.77)$ than in the vertical-horizontal $(M=0.68)$ orientations.

The forearm condition $\times$ orientation interaction was significant $[F(3,66)=5.9, p<.005]$ (Figure 2), meaning that the oblique effect was not present (mean for verticalhorizontal $=0.72$, mean for $\left.45^{\circ}-135^{\circ}=0.68\right)$ in the supported-forearm condition $[F(1,22)=0.04, p>.25]$ and was present (mean for vertical-horizontal $=0.65$, mean for $45^{\circ}-135^{\circ}=0.87$ ) in the unsupported-forearm condition $[F(1,22)=39, p<.001]$. The effect of forearm condition did not affect the scores in the verticalhorizontal settings $[F(1,22)=2.1, p=.15]$, whereas it was significant in the oblique settings $[F(1,22)=16.4$, $p<.001$ ]: errors were higher in the unsupported-forearm than in the supported-forearm conditions.

\section{Discussion}

The main finding of this experiment is that, in the horizontal plane, the oblique effect appeared in the

Table $1 \mathrm{~B}$

Mean Absolute Angular Errors in Degrees and Log Transformed (in Parentheses), With Standard Deviations, as a Function of Forearm Condition and Stimulus Orientation in Experiment 1

\begin{tabular}{|c|c|c|c|c|c|c|c|c|}
\hline \multirow[b]{3}{*}{ Forearm } & \multicolumn{8}{|c|}{ Orientation } \\
\hline & \multicolumn{2}{|c|}{ Vertical } & \multicolumn{2}{|c|}{$+45^{\circ}$} & \multicolumn{2}{|c|}{ Horizontal } & \multicolumn{2}{|c|}{$+135^{\circ}$} \\
\hline & $M$ & $S D$ & $M$ & $S D$ & $M$ & $S D$ & $M$ & $S D$ \\
\hline Unsupported & $\begin{array}{c}3.4^{\circ} \\
(0.61)\end{array}$ & $\begin{array}{c}1.5^{\circ} \\
(0.19)\end{array}$ & $\begin{array}{c}7.6^{\circ} \\
(0.91)\end{array}$ & $\begin{array}{c}3.6^{\circ} \\
(0.17)\end{array}$ & $\begin{array}{c}4.2^{\circ} \\
(0.68)\end{array}$ & $\begin{array}{c}2.2^{\circ} \\
(0.21)\end{array}$ & $\begin{array}{c}6.3^{\circ} \\
(0.83)\end{array}$ & $\begin{array}{c}2.8^{\circ} \\
(0.18)\end{array}$ \\
\hline Supported & $\begin{array}{c}4.3^{\circ} \\
(0.68)\end{array}$ & $\begin{array}{c}2.9^{\circ} \\
(0.21)\end{array}$ & $\begin{array}{c}3.6^{\circ} \\
(0.63)\end{array}$ & $\begin{array}{c}1.9^{\circ} \\
(0.18)\end{array}$ & $\begin{array}{c}5.1^{\circ} \\
(0.76)\end{array}$ & $\begin{array}{c}2.2^{\circ} \\
(0.15)\end{array}$ & $\begin{array}{c}4.7^{\circ} \\
(0.72)\end{array}$ & $\begin{array}{c}2.5^{\circ} \\
(0.18)\end{array}$ \\
\hline
\end{tabular}




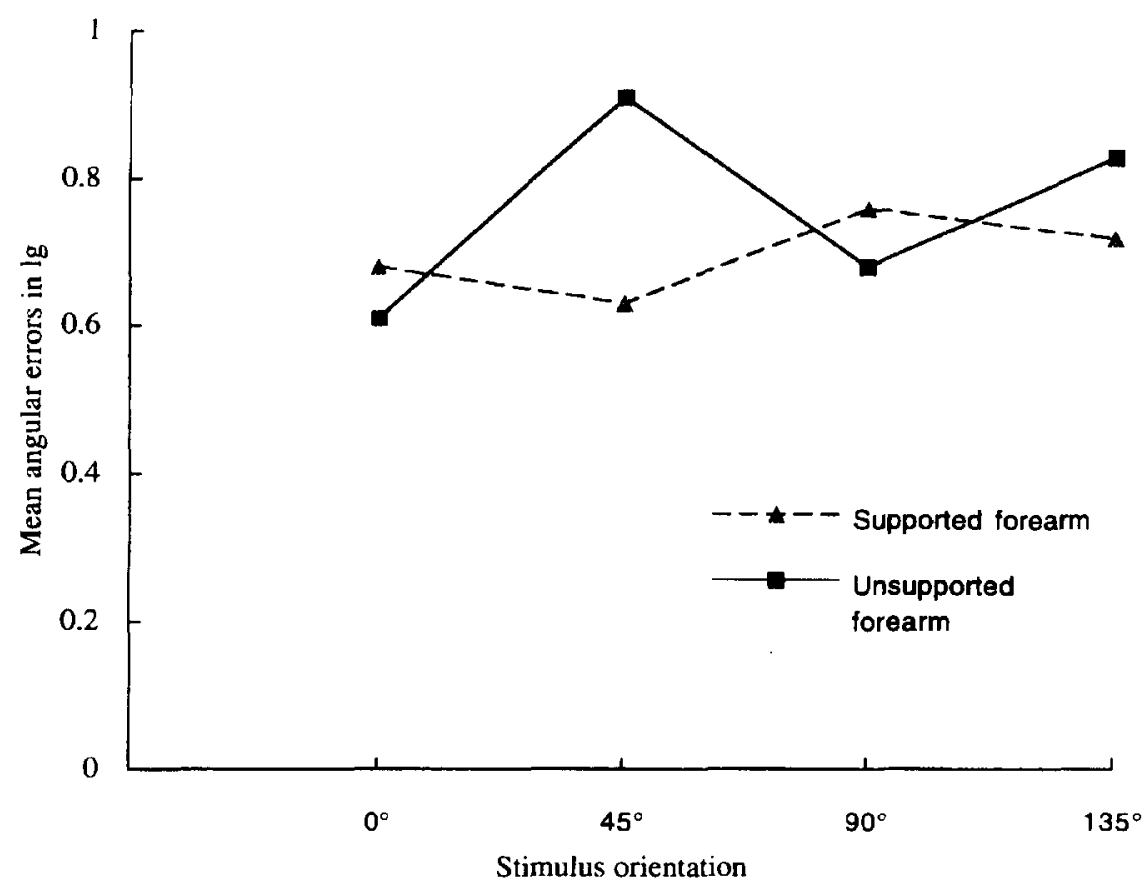

Figure 2. Mean absolute angular errors in log as a function of forearm condition and stimulus orientation in the horizontal plane: Experiment 1.

unsupported-forearm condition, in which the magnitude of gravitational cues was natural because the stimulus rod was away from the disk. By contrast, in the supportedforearm condition, in which these cues were reduced because the rod was directly in contact with the disk, the oblique effect was absent. The latter observation replicated Appelle and Countryman's (1986) and Gentaz and Hatwell's (1995) findings.

On the one hand, Appelle and Countryman's (1986) interpretation of the role of movement coding in the haptic oblique effect was not confirmed because the oblique effect was present in the unsupported-forearm condition, although the same hand explored and set the response rod. On the other hand, these results are consistent with the hypothesis that the haptic oblique effect depends on the magnitude of gravitational cues. However, the fact that errors increased in setting oblique orientations in the unsupported-forearm condition was not consistent with our first hypothesis assuming that the oblique effect would stem from the enhanced accuracy of verticalhorizontal settings when gravitational cues were available. Experiments 2 and 3 were further designed to extend this study to the frontal and sagittal planes and to introduce other modifications of the gravity environment.

\section{EXPERIMENT 2}

In this experiment, the gravitational cues were reduced by a physical device (consisting of a set of pulleys and weights) that lightened the subject's forearm. The disk-rod display was the same as in the unsupportedforearm condition of Experiment 1; that is, the rod was
$8 \mathrm{~cm}$ distant from the disk, and the three planes were tested (horizontal, frontal, and sagittal). If the magnitude and the variability of gravitational cues during scanning were involved in orientation coding, the amount of the oblique effect and of the plane effect (more accurate performance in the frontal and sagittal planes than in the horizontal plane) would be lower in the lightened-forearm condition than in a natural control condition (without lightening). This would derive from the fact that fewer gravitational cues would be available in the lightenedforearm condition. As a result, errors would increase in the setting of vertical-horizontal orientations, especially in the frontal and sagittal planes. The difference in accuracy between vertical-horizontal and oblique orientations, and between frontal-sagittal and horizontal planes, would therefore decrease.

\section{Method}

Subjects. The subjects were 48 right-handed undergraduate female students (sec explanations below) in psychology and sociology who participated in the experiment in exchange for extra course credit. Their handedness was assessed with the use of Bryden's five-item hand preference questionnaire.

Apparatus. The apparatus had the $\operatorname{rod} 8 \mathrm{~cm}$ distant from the disk (Figure 1A). To test subjects in the three planes of space, the disk and rod could be positioned in the frontal plane (like the surface of a blackboard), in the horizontal plane (like the surface of a table), or in the sagittal plane (in the median plane passing through the midline of the subject's head). These three planes were orthogonal to each other. The lightening mechanism was composed of a strap tied up to the subject's forearm. This strap was connected with a suspended weight by a cable sliding through two fixed pulleys (Figure 3 ). The height of the disk was adjusted with reference to the subject's height: in the frontal and sagittal 


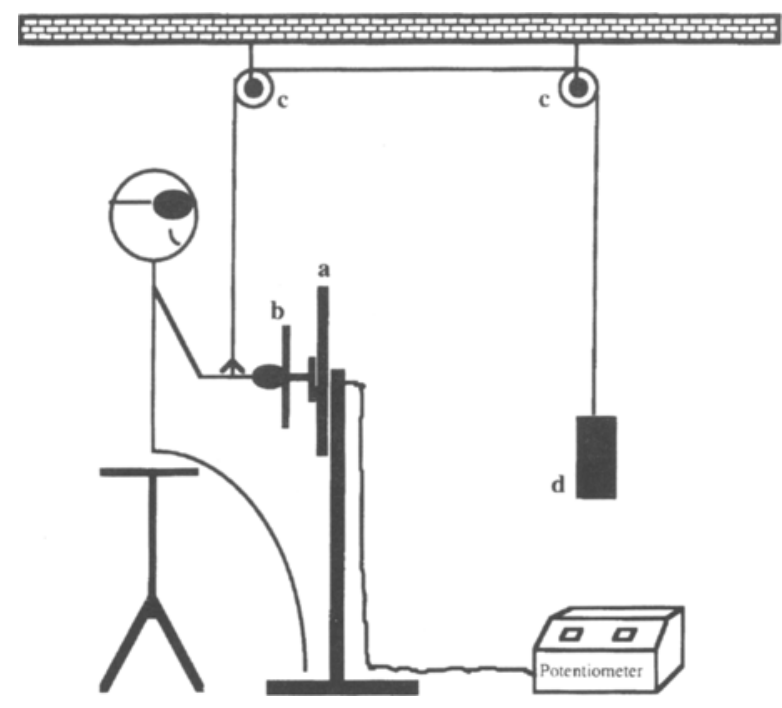

Figure 3. Apparatus showing how the subject's forearm was lightened; in this example, the disk was positioned in the frontal plane: Experiment 2. a, disk; b, stimulus rod; c, pulleys; d, weighted block.

planes, the top of the disk was at the level of the subject's shoulders; in the horizontal plane, the rod was positioned at a level under the subject's breast.

Experimental conditions and Procedure. Each subject was tested under one of two forearm conditions. In the control condition (the natural condition), the subjects were not connected to the lightening device and they explored the rod naturally. This condition was the same as the unsupported-forearm condition of Experiment 1 . In the second condition (the lightened-forearm condition), the subjects were connected to the pulleys and explored the rod with their forearm lightened (Figure 3 ). The mechanism allowing lightening could not be seen by the subject, because it was installed after blindfolding. The weight suspended to the pulleys varied from one subject to another. To find the appropriate weight for each subject, the experimenter tested different weights (in ascending and descending series, by steps of $10 \mathrm{~g}$ of sand) and asked the subject to indicate the weight "with which her arm did not feel any pressure pulling it upward or downward" when the forearm was at the level of the center of the disk for the frontal and sagittal planes (Figure 3 ) or $5 \mathrm{~cm}$ above the rod for the horizontal plane. This weight was selected as the most appropriate to un- weight the subject's arm. Of course, these appropriate weights depended on the subject's body characteristics (size and weight). The mean selected weight was $760 \mathrm{~g}$ (range: 590-960 g). To decrease the intersubject variability of the selected weights, only female subjects were tested. It was reasonable to think that the exclusion of males would have no consequence in this study. Contrary to what occurs in vision, where spatial abilities have often been found to vary according to gender (Voyer, Voyer, \& Bryden, 1995), in haptics no effect of gender was observed in Gentaz and Hatwell's (1995) research, or, more generally, in studies on haptic modality (Berthiaume, Robert, St-Onge, \& Pelletier, 1993; Walker, 1972). Informal observations showed that the lightening device did not modify significantly the type of movements performed in this experiment: subjects actively moved their armhand system to scan the rod.

For each forearm condition, one third of the subjects were tested with the disk positioned in the horizontal plane, another third were tested with the disk in the frontal plane, and the remaining third were tested with the disk in the sagittal plane. Half the subjects used the right hand and the other half used the left hand. The rest of the procedure was the same as in Experiment 1.

\section{Results}

The mean signed errors for each condition are shown in Table 2A. The attribution of sign was the same as in Experiment 1 . A preliminary ANOVA showed that hand had no effect and did not interact with any other factor. Consequently, results were collapsed across hand. A 2 (forearm condition) $\times 3$ (plane) $\times 4$ (orientation) ANOVA (with repeated measures on the last factor) on signed errors revealed no significant effect of orientation $[F(3,126)$ $=0.99, p>.25]$, plane $[F(2,42)=0.36, p>.25]$, or forearm condition $[F(1,42)=0.22, p>.25]$, nor were there any interactions between these three factors: plane $x$ forearm condition $[F(2,42)=0.64, p>.25]$, orientation $\times$ plane $[F(6,126)=0.5, p>.25]$, orientation $\times$ forearm condition $[F(3,126)=1.5, p>.20]$, orientation $\times$ plane $\times$ forearm condition $[F(6,126)=0.45, p>.25]$. Further $t$ tests compared the mean values of each condition with zero, in order to determine whether there were systematic directional errors. Results of these tests (Table 2A) showed that most of the mean errors were positive, with a tendency to overshoot. However, only 2 out of 24 values were significant and only 1 approached significance. When the 24 conditions were collapsed, the global mean

Table 2A

Mean Signed Angular Errors, With Standard Deviations, as a Function of Forearm Condition, Plane, and Stimulus Orientation in Experiment 2

\begin{tabular}{|c|c|c|c|c|c|c|c|c|}
\hline \multirow[b]{3}{*}{ Plane } & \multicolumn{8}{|c|}{ Orientation } \\
\hline & \multicolumn{2}{|c|}{ Vertical } & \multicolumn{2}{|c|}{$+45^{\circ}$} & \multicolumn{2}{|c|}{ Horizontal } & \multicolumn{2}{|c|}{$+135^{\circ}$} \\
\hline & $M$ & $S D$ & $M$ & $S D$ & $M$ & $S D$ & $M$ & $S D$ \\
\hline \multicolumn{9}{|c|}{ Natural Forearm Condition } \\
\hline Horizontal & $-0.9^{\circ}$ & $5.2^{\circ}$ & $1.6^{\circ}$ & $7.7^{\circ}$ & $-0.1^{\circ}$ & $4.1^{\circ}$ & $0.7^{\circ}$ & $4.9^{\circ}$ \\
\hline Frontal & $0.7^{\circ}$ & $5.8^{\circ}$ & $-0.1^{\circ}$ & $8.9^{\circ}$ & $-0.2^{\circ}$ & $2.5^{\circ}$ & $5.9^{\circ *}$ & $3.8^{\circ}$ \\
\hline Sagittal & $-0.2^{\circ}$ & $3.4^{\circ}$ & $1.5^{\circ}$ & $6.1^{\circ}$ & $3.0^{\circ+}$ & $4.1^{\circ}$ & $2.2^{\circ}$ & $8.3^{\circ}$ \\
\hline \multicolumn{9}{|c|}{ Lightened Forearm Condition } \\
\hline Horizontal & $0.9^{\circ}$ & $9.8^{\circ}$ & $2.9^{\circ \dagger}$ & $3.2^{\circ}$ & $1.7^{\circ}$ & $4.3^{\circ}$ & $-0.4^{\circ}$ & $5.8^{\circ}$ \\
\hline Frontal & $0.1^{\circ}$ & $6.8^{\circ}$ & $2.6^{\circ}$ & $6.0^{\circ}$ & $-0.8^{\circ}$ & $3.9^{\circ}$ & $0.1^{\circ}$ & $4.9^{\circ}$ \\
\hline Sagittal & $0.1^{\circ}$ & $6.8^{\circ}$ & $2.6^{\circ}$ & $6.0^{\circ}$ & $-0.8^{\circ}$ & $3.9^{\circ}$ & $0.1^{\circ}$ & $4.9^{\circ}$ \\
\hline
\end{tabular}


error was positive $(M=0.97, S D=5.66)$ and significant $[t(191)=2.36, p \leq .02]$. The reason for this tendency to overshoot is not clear.

The mean absolute errors (in degrees and in $\log$ ) for each condition are shown in Table 2B. For the same reasons as in Experiment 1, a logarithmic transformation, $\log (x+1)$ was carried out on each angular difference for each subject in each condition.

A preliminary ANOVA of absolute errors in log showed that hand had no effect and did not interact with any other factor. Consequently, results were collapsed across hand. A 2 (forearm condition) $\times 3$ (plane) $\times 4$ (orientation) ANOVA (with repeated measures on the last factor) of absolute errors in log revealed a main effect of orientation $[F(3,126)=11.6, p<.001]$, showing fewer errors in the vertical $(M=0.76)$ and the horizontal orientations $(M=0.74)$, which did not differ $[F(1,42)=$ $0.43, p>.25]$, than in the $45^{\circ}(M=0.89)$ and the $135^{\circ}$ $(M=0.90)$ obliques $[F(1,42)=31, p<.001]$, which did not differ $[F(1,42)=0.1, p>.25]$. There was a main effect of forearm condition $[F(1,42)=6.2, p<.025]$, with more errors in the lightened-forearm condition $(M=$ $0.87)$ than in the natural (control) condition $(M=0.78)$. The plane effect failed to reach significance $[F(2,42)=$ $2.2, p=.10]$ and did not interact with orientation $[F(6,126)$ $=1.5, p>.15]$ or forearm condition $[F(2,42)=0.11, p>$ $.25]$, or with both factors $[F(6,126)=0.83, p>.25]$.

The forearm condition $\times$ orientation interaction was significant $[F(3,126)=2.9, p<.05]$ (Figure 4): forearm conditions affected only the vertical-horizontal settings $[F(1,42)=11.9, p<.001]$, not the oblique ones $[F(1,42)$ $=0.28, p>.25]$. In these vertical-horizontal settings, errors were higher in the lightened condition $(M=0.83)$ than in the natural (control) condition $(M=0.67)$, whereas they were similar in the oblique settings (lightened = 0.91 and natural $=0.88$ ). The oblique effect, however, was significant in both the lightened condition (for vertical-horizontal, $M=0.83$; for $45^{\circ}-135^{\circ}, M=0.91$ )
$[F(1,42)=4.8, p<.05]$ and the natural condition (for vertical-horizontal, $M=0.67$; for $45^{\circ}-135^{\circ}, M=0.88$ ) $[F(1,42)=32.9, p<.001]$.

\section{Discussion}

These results support the assumption that the haptic oblique effect is linked to the magnitude of the gravitational cues provided by the arm-hand system when it scans in the three spatial planes. Although the oblique effect appeared here in the two forearm conditions, its magnitude decreased in the lightened-forearm condition, in which the magnitude of gravitational cues was lowered. This decrease of the oblique effect was due to a lower accuracy of the coding of the vertical-horizontal orientations as opposed to obliques (which did not vary according to the forearm condition). This result is consistent with our hypotheses, but it is opposite to what was observed in Experiment 1, in which the oblique effect observed in the horizontal plane in the unsupported-forearm condition was due to increased errors in the oblique settings. This difference may have resulted from the fact that only the horizontal plane was tested in Experiment 1, whereas the three planes were studied in the present experiment.

On the other hand, the variability of the gravitational cues during scanning had no effect on orientation coding accuracy. These cues varied as a function of the plane in which the task was performed, because in the lightenedforearm condition, higher forces were required when the forearm moved downward and lower forces were required when it moved upward. These variations due to acceleration were present in the frontal and sagittal planes but were absent in the horizontal plane. However, contrary to our hypotheses, the plane effect was not significant and there was no interaction between forearm condition and plane.

In Experiments 1 and 2, we tested the role of decreased gravitational cues as compared with natural conditions. Experiment 3 was designed to study the reverse effect-

Table 2B

Mean Absolute Angular Errors in Degrees and Log Transformed (in Parentheses), With Standard Deviations, as a Function of Forearm Condition, Plane, and Stimulus Orientation in Experiment 2

\begin{tabular}{|c|c|c|c|c|c|c|c|c|}
\hline \multirow[b]{3}{*}{ Plane } & \multicolumn{8}{|c|}{ Orientation } \\
\hline & \multicolumn{2}{|c|}{ Vertical } & \multicolumn{2}{|c|}{$+45^{\circ}$} & \multicolumn{2}{|c|}{ Horizontal } & \multicolumn{2}{|c|}{$+135^{\circ}$} \\
\hline & $M$ & $S D$ & $M$ & $S D$ & $M$ & $S D$ & $M$ & $S D$ \\
\hline \multicolumn{9}{|c|}{ Natural Forearm Condition } \\
\hline Horizontal & $\begin{array}{c}5.5^{\circ} \\
(0.77)\end{array}$ & $\begin{array}{c}3.2^{\mathbf{0}} \\
(0.21)\end{array}$ & $\begin{array}{c}7.7^{\circ} \\
(0.88)\end{array}$ & $\begin{array}{c}4.9^{\circ} \\
(0.24)\end{array}$ & $\begin{array}{c}5.2^{\circ} \\
(0.76)\end{array}$ & $\begin{array}{c}2.1^{\circ} \\
(0.18)\end{array}$ & $\begin{array}{c}6.9^{\circ} \\
(0.87)\end{array}$ & $\begin{array}{c}3.1^{\circ} \\
(0.17)\end{array}$ \\
\hline Frontal & $\begin{array}{c}3.8^{\circ} \\
(0.64)\end{array}$ & $\begin{array}{c}2.0^{\circ} \\
(0.20)\end{array}$ & $\begin{array}{c}9.1^{\circ} \\
(0.95)\end{array}$ & $\begin{array}{c}4.4^{\circ} \\
(0.26)\end{array}$ & $\begin{array}{c}3.1^{\circ} \\
(0.60)\end{array}$ & $\begin{array}{c}1.0^{\circ} \\
(0.13)\end{array}$ & $\begin{array}{c}7.4^{\circ} \\
(0.88)\end{array}$ & $\begin{array}{c}4.3^{\circ} \\
(0.22)\end{array}$ \\
\hline Sagittal & $\begin{array}{c}2.9^{\circ} \\
(0.57)\end{array}$ & $\begin{array}{c}1.4^{\circ} \\
(0.18)\end{array}$ & $\begin{array}{c}6.5^{\circ} \\
(0.84)\end{array}$ & $\begin{array}{c}2.7^{\circ} \\
(0.19)\end{array}$ & $\begin{array}{c}4.3^{\circ} \\
(0.68)\end{array}$ & $\begin{array}{c}2.8^{\circ} \\
(0.22)\end{array}$ & $\begin{array}{c}7.8^{\circ} \\
(0.90)\end{array}$ & $\begin{array}{c}4.7^{\mathrm{o}} \\
(0.20)\end{array}$ \\
\hline \multicolumn{9}{|c|}{ Lightened Forearm Condition } \\
\hline Horizontal & $\begin{array}{c}8.5^{\circ} \\
(0.94)\end{array}$ & $\begin{array}{c}4.0^{\circ} \\
(0.19)\end{array}$ & $\begin{array}{c}8.0^{\circ} \\
(0.91)\end{array}$ & $\begin{array}{c}4.3^{\circ} \\
(0.20)\end{array}$ & $\begin{array}{c}6.8^{\circ} \\
(0.87)\end{array}$ & $\begin{array}{c}2.4^{\circ} \\
(0.12)\end{array}$ & $\begin{array}{l}10.1^{\circ} \\
(1.00)\end{array}$ & $\begin{array}{c}5.0^{\circ} \\
(0.20)\end{array}$ \\
\hline Frontal & $\begin{array}{c}6.3^{\circ} \\
(0.81)\end{array}$ & $\begin{array}{c}3.8^{\circ} \\
(0.21)\end{array}$ & $\begin{array}{c}8.3^{\circ} \\
(0.94)\end{array}$ & $\begin{array}{c}2.9^{\circ} \\
(0.15)\end{array}$ & $\begin{array}{c}5.8^{\circ} \\
(0.80)\end{array}$ & $\begin{array}{c}2.7^{\circ} \\
(0.16)\end{array}$ & $\begin{array}{c}6.2^{\circ} \\
(0.81)\end{array}$ & $\begin{array}{c}3.4^{\circ} \\
(0.21)\end{array}$ \\
\hline Sagittal & $\begin{array}{c}6.7^{\circ} \\
(0.82) \\
\end{array}$ & $\begin{array}{c}4.1^{\circ} \\
(0.26) \\
\end{array}$ & $\begin{array}{c}6.3^{\circ} \\
(0.82)\end{array}$ & $\begin{array}{c}3.1^{\circ} \\
(0.20)\end{array}$ & $\begin{array}{c}4.7^{\circ} \\
(0.71)\end{array}$ & $\begin{array}{c}2.7^{\circ} \\
(0.23)\end{array}$ & $\begin{array}{c}8.5^{\circ} \\
(0.96)\end{array}$ & $\begin{array}{c}2.9^{\circ} \\
(0.14)\end{array}$ \\
\hline
\end{tabular}




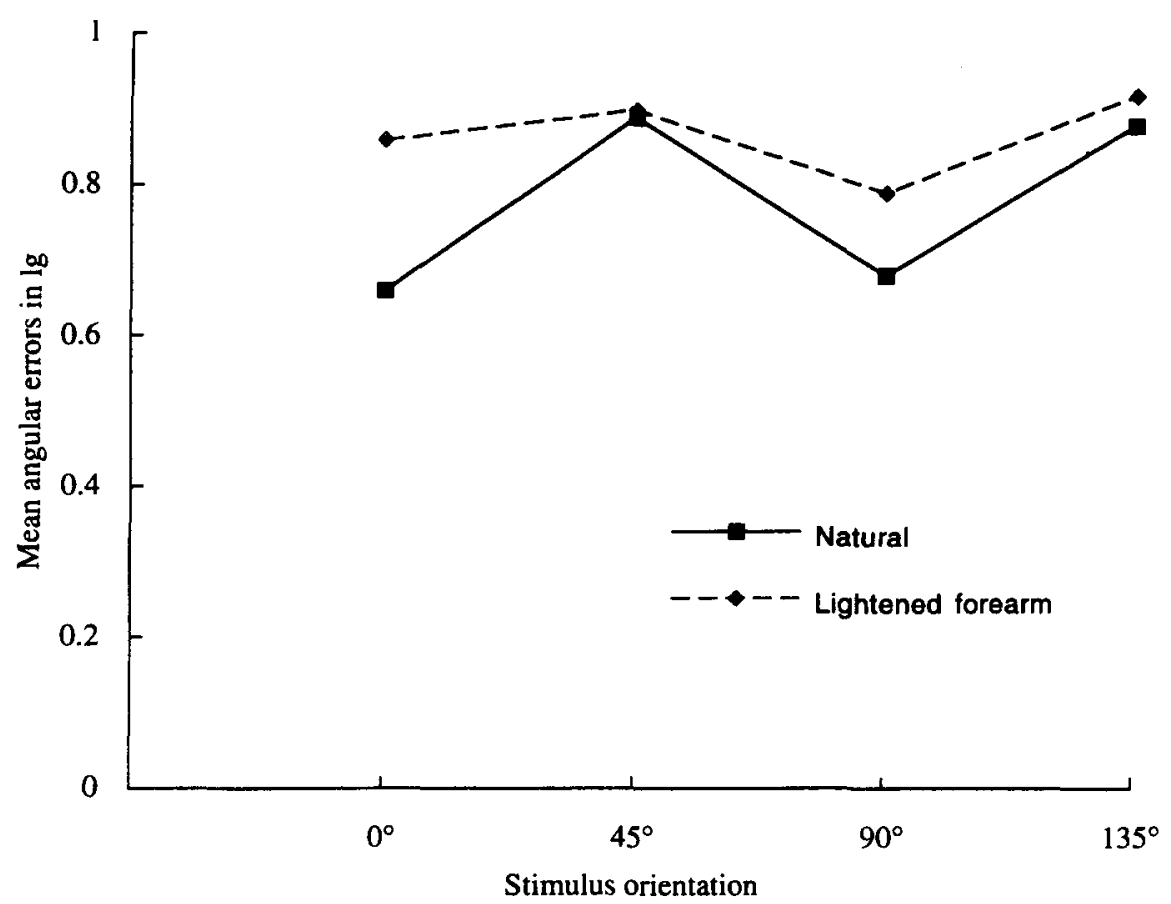

Figure 4. Mean absolute angular errors in log as a function of forearm condition and stimulus orientation: Experiment 2.

to determine whether increasing gravitational cues would increase correlatively the amount of the oblique effect and the plane effect.

\section{EXPERIMENT 3}

In order to increase the magnitude of gravitational cues in the three planes, the gravity constraints were enhanced by loading the subject's forearm. This forearm was equipped with a bracelet weighing either 500 or $1,000 \mathrm{~g}$. A control group had no bracelet and performed the task in the same natural condition as in Experiment 2. If the magnitude and the variability of gravitational cues were involved in orientation coding, both the oblique effect and the plane effect would be affected by these variations. We predicted that, because more gravitational cues are available in it, errors in the loaded forearm conditions would decrease in the setting of vertical-horizontal orientations and in the frontal and sagittal planes. Consequently, the oblique effect and the plane effect would increase.

\section{Method}

Subjects. The subjects were 72 right-handed undergraduate female students (see explanations below) in psychology and sociology who participated in the experiment in exchange for extra course credit. Their handedness was assessed with the use of Bryden's five-item hand preference questionnaire.

Apparatus and Procedure. The disk-rod display was the same as in the natural control condition of Experiment 2, with the stimulus rod $8 \mathrm{~cm}$ distant from the disk surface. The disk was positioned in one of the three planes. In one natural (control) condition (W1), the subject's forearm was not weighted and the gravi- tational cues depended only on the normal forearm weight of each subject. In the other two conditions, the subject's forearm was loaded with a bracelet (like those used by joggers) weighing either $500 \mathrm{~g}$ (W2) or $1,000 \mathrm{~g}$ (W3). In the latter conditions, gravitational cues depended on the subject's forearm weight added to the weight of the bracelet. The subjects could not see the bracelet because it was installed after blindfolding. As in Experiment 2, only females were tested in order to reduce the variability of body size and forearm weight. Except in the forearm conditions, the procedure was the same as in Experiments 1 and 2. Each subject was tested under one of the three forearm conditions ( 24 subjects in each group).

\section{Results}

The mean signed errors for each condition are shown in Table $3 \mathrm{~A}$. The attribution of sign was the same as in Experiments 1 and 2. A preliminary ANOVA of signed errors showed that hand had no effect and did not interact with any other factor. Consequently, results were collapsed across hand. A 3 (forearm condition) $\times 3$ (plane) $\times 4$ (orientation) ANOVA (with repeated measures on the last factor) revealed no main effect of orientation $[F(3,189)=$ $1.7, p=.15]$, plane $[F(2,63)=0.07, p>.25]$, or forearm condition $[F(2,63)=0.5, p>.25]$. There was an interaction between orientation and plane $[F(6,189)=4.5$, $p<.001]$. It means that, in the frontal plane, there was an effect of orientation $[F(3,63)=16.6, p<.001]$ only in oblique settings (Figure 5$)$ : errors were negative $\left(-2.5^{\circ}\right)$ in the $+45^{\circ}$ oblique, whereas errors were positive $\left(+4.4^{\circ}\right)$ in the $+135^{\circ}$ oblique [respectively, $F(1,21)=20.1, p<$ .001 , and $F(1,21)=8, p<.025]$. This bias was similar to the "normalization effect" (a tendency to reproduce 
Table 3A

Mean Signed Angular Errors in Degrees, With Standard Deviations, as a Function of Forearm Condition, Plane, and Stimulus Orientation in Experiment 3

\begin{tabular}{|c|c|c|c|c|c|c|c|c|}
\hline \multirow[b]{3}{*}{ Plane } & \multicolumn{8}{|c|}{ Orientation } \\
\hline & \multicolumn{2}{|c|}{ Vertical } & \multicolumn{2}{|c|}{$+45^{\circ}$} & \multicolumn{2}{|c|}{ Horizontal } & \multicolumn{2}{|c|}{$+135^{\circ}$} \\
\hline & $M$ & $S D$ & $M$ & $S D$ & $M$ & $S D$ & $M$ & $S D$ \\
\hline \multicolumn{9}{|c|}{ W1: Natural Forearm Condition } \\
\hline Horizontal & $-1.1^{\circ}$ & $4.5^{\circ}$ & $0.1^{\circ}$ & $5.3^{\circ}$ & $0.7^{\circ}$ & $3.9^{\circ}$ & $4.4^{10 \dagger}$ & $5.9^{\circ}$ \\
\hline Frontal & $0.2^{\circ}$ & $3.0^{\circ}$ & $2.4^{\circ}$ & $6.9^{\circ}$ & $0.7^{\circ}$ & $2.6^{\circ}$ & $4.4^{\circ \dagger}$ & $5.6^{\circ}$ \\
\hline Sagittal & $-0.6^{\circ}$ & $3.3^{\circ}$ & $1.7^{\circ}$ & $3.9^{\circ}$ & $2.7^{\circ}$ & $4.3^{\circ}$ & $1.9^{\circ}$ & $8.9^{\circ}$ \\
\hline \multicolumn{9}{|c|}{ W2: With $500 \mathrm{~g}$} \\
\hline Horizontal & $1.3^{\circ}$ & $6.7^{\circ}$ & $3.4^{\circ}$ & $6.8^{\circ}$ & $2.7^{\circ}$ & $4.2^{\circ}$ & $-3.6^{\circ}$ & $5.9^{\circ}$ \\
\hline Frontal & $2.3^{\circ \dagger}$ & $3.1^{\circ}$ & $-4.9^{\circ *}$ & $1.3^{\circ}$ & $1.2^{\circ}$ & $3.1^{\circ}$ & $4.4^{\circ *}$ & $3.3^{\circ}$ \\
\hline Sagittal & $0.2^{\circ}$ & $4.2^{\circ}$ & $1.3^{\circ}$ & $5.4^{\circ}$ & $2.8^{\circ}$ & $3.5^{\circ}$ & $2.8^{\circ}$ & $5.0^{\circ}$ \\
\hline \multicolumn{9}{|c|}{ W3: With $1,000 \mathrm{~g}$} \\
\hline Horizontal & $5.9^{\circ+}$ & $8.1^{\circ}$ & $1.5^{\circ}$ & $6.1^{\circ}$ & $-2.3^{\circ}$ & $5.9^{\circ}$ & $-1.3^{\circ}$ & $5.2^{\circ}$ \\
\hline Frontal & $2.3^{\circ+}$ & $3.1^{\circ}$ & $-4.9^{\circ *}$ & $1.3^{\circ}$ & $1.2^{\circ}$ & $3.1^{\circ}$ & $4.4^{0 *}$ & $3.4^{\circ}$ \\
\hline Sagittal & $0.8^{\circ}$ & $2.7^{\circ}$ & $0.7^{\circ}$ & $2.2^{\circ}$ & $-0.5^{\circ}$ & $2.8^{\circ}$ & $1.3^{\circ}$ & $3.4^{\circ}$ \\
\hline
\end{tabular}

Note-Probabilities for $t$ tests are as follows: ${ }^{*} p<.01 .+{ }^{+} .10>p>$ .05 .

oblique orientations closer to the vertical) often observed in the visual modality; see Howard, 1982). No directional errors were observed in the horizontal $[F(3,63)=1.32$, $p>.25]$ or sagittal planes $[F(3,63)=0.9, p>.25]$. There was also an orientation $\times$ plane $\times$ forearm condition interaction $[F(6,189)=2.3, p<.01]$, showing that the abovementioned plane $x$ orientation interaction was present only in the $\mathrm{W} 2$ and $\mathrm{W} 3$ conditions. The reason why normalization was present only in the frontal plane and in the loaded forearm conditions is unclear.

Further $t$ tests compared the mean values of each condition with zero, in order to determine whether there were systematic directional errors. Results of these tests (Table 3A) showed that 4 out of 36 values were significant and 6 approached significance. The significant values were those obtained in the frontal plane, and their direction was consistent with the normalization effect revealed in this plane by the ANOVA. When the 36 conditions of this experiment were collapsed, the global mean error was positive $(M=1.09, S D=5.08)$ and significant $[t(287)=3.63, p<.002]$. As in the preceding experiments, the subjects tended to overshoot when setting the rod. We further collapsed all the 68 conditions studied in the three experiments reported here ( 8 conditions in Experiment 1, 24 conditions in Experiment 2, and 36 conditions in Experiment 3), testing 144 subjects and 4 orientations. The general mean error was positive $(M=$ $1.09, S D=5.14)$ and significant $[t(575)=5.19, p<$ $.001]$. This confirmed that there was a systematic tendency to slightly overshoot. The interpretation of this tendency would require further research.

The mean absolute errors (in degrees and in $\log$ ) for each condition are shown in Table 3B. As in Experiments 1 and 2, a logarithmic transformation, $\log (x+1)$, was carried out on each angular difference for each subject in each condition.
A preliminary ANOVA on absolute errors in log showed that hand had no effect and did not interact with any other factor. Consequently, results were collapsed across hand. Another ANOVA ( 3 forearm conditions $x$ 3 planes $\times 4$ orientations, with repeated measures on the last factor) on absolute errors in log showed a main effect of orientation $[F(3,189)=14.5, p<.001]$ revealing fewer errors in the vertical $(M=0.68)$ and horizontal orientations $(M=0.73)$, which did not differ $[F(1,63)=$ $2, p>.15]$, than in the $45^{\circ}(M=0.86)$ and the $135^{\circ}(M=$ $0.84)$ obliques $[F(1,63)=35.2, p<.001]$, which did not differ $[F(1,63)=0.95, p>.25]$. Forearm conditions had no main effect $[F(2,63)=1.2, p>.25]$ and did not interact with orientation $[F(6,189)=1.6, p>.13]$.

There was a main effect of plane $[F(2,63)=15.2, p<$ $.001]$, with more errors in the horizontal plane $(M=0.87)$ than in the frontal and sagittal planes $[F(1,63)=29, p<$ $.001]$, which did not differ $(M=0.74$ and $M=0.72$, respectively) $[F(1,42)=0.89, p>.25]$. The plane $\times$ forearm interaction was significant $[F(4,63)=3.7, p<.01]$ (Figure 6). It means that the plane affected the scores when the forearm was weighted with $500 \mathrm{~g}$ (W2) and $1,000 \mathrm{~g}(\mathrm{~W} 3)$ [respectively, $F(2,21)=6.1, p<.01$, and $F(2,21)=14.6, p<.001]$ and had no effect in the natural control condition (W1) $[F(2,21)=1.85, p>.25]$. In the $\mathrm{W} 2$ condition, errors were higher in the horizontal plane $(M=0.89)$ than in the frontal $(M=0.73)$ and sagittal $(M=0.76)$ planes $[F(1,21)=11.6, p<.01]$, which did not differ $[F(1,14)=0.4, p>.25]$. Similarly, in the W3 condition, errors were higher in the horizontal plane $(M=0.9)$ than in the frontal $(M=0.69)$ and sagittal $(M=0.66)$ planes $[F(1,21)=28.6, p<.01]$, which did not differ $[F(1,14)=0.7, p>.25]$. By contrast, forearm condition did not affect the scores in the horizontal plane $[F(2,21)=1.1, p>.25]$ and failed to reach significance in the frontal $[F(2,21)=2.9, p>.08]$ and sagittal

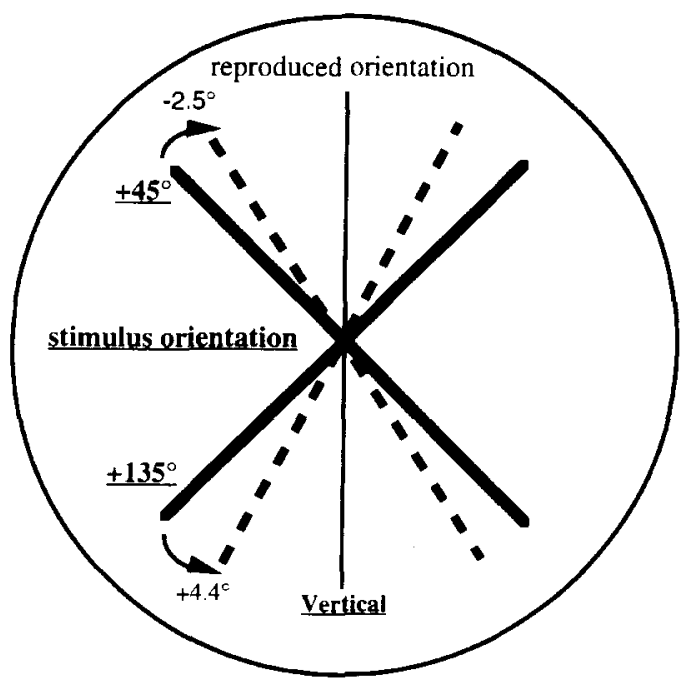

Figure 5. Mean signed angular errors in degrees as a function of oblique orientations in the frontal plane: Experiment 3. 
Table 3B

\begin{tabular}{|c|c|c|c|c|c|c|c|c|}
\hline \multirow[b]{3}{*}{ Plane } & \multicolumn{8}{|c|}{ Orientation } \\
\hline & \multicolumn{2}{|c|}{ Vertical } & \multicolumn{2}{|c|}{$+45^{\circ}$} & \multicolumn{2}{|c|}{ Horizontal } & \multicolumn{2}{|c|}{$+135^{\circ}$} \\
\hline & $\vec{M}$ & $S D$ & $M$ & $\overline{S D}$ & $M$ & $S D$ & $\bar{M}$ & $\overline{S D}$ \\
\hline \multicolumn{9}{|c|}{ W1: Natural Forearm Condition } \\
\hline Horizontal & $\begin{array}{c}4.7^{\circ} \\
(0.71)\end{array}$ & $\begin{array}{c}2.9^{\circ} \\
(0.21)\end{array}$ & $\begin{array}{c}6.8^{\circ} \\
(0.85)\end{array}$ & $\begin{array}{c}4.3^{\circ} \\
(0.19)\end{array}$ & $\begin{array}{c}4.9^{\circ} \\
(0.75)\end{array}$ & $\begin{array}{c}2.1^{\circ} \\
(0.17)\end{array}$ & $\begin{array}{c}7.6^{\circ} \\
(0.88)\end{array}$ & $\begin{array}{r}4.9^{\circ} \\
(0.22\end{array}$ \\
\hline Frontal & $\begin{array}{c}3.8^{\circ} \\
(0.64)\end{array}$ & $\begin{array}{c}1.9^{\circ} \\
(0.20)\end{array}$ & $\begin{array}{c}9.3^{\circ} \\
(0.96)\end{array}$ & $\begin{array}{c}4.5^{\circ} \\
(0.26)\end{array}$ & $\begin{array}{c}4.2^{\circ} \\
(0.71)\end{array}$ & $\begin{array}{c}1.2^{\circ} \\
(0.10)\end{array}$ & $\begin{array}{c}8.3^{\circ} \\
(0.95)\end{array}$ & $\begin{array}{c}2.7^{\circ} \\
(0.13)\end{array}$ \\
\hline Sagittal & $\begin{array}{c}3.0^{\circ} \\
(0.58)\end{array}$ & $\begin{array}{c}1.3^{\circ} \\
(0.17)\end{array}$ & $\begin{array}{c}5.3^{\circ} \\
(0.79)\end{array}$ & $\begin{array}{c}2.3^{\circ} \\
(0.17)\end{array}$ & $\begin{array}{c}4.1^{\circ} \\
(0.64)\end{array}$ & $\begin{array}{c}3.1^{\circ} \\
(0.26)\end{array}$ & $\begin{array}{c}8.8^{\circ} \\
(0.95)\end{array}$ & $\begin{array}{c}4.9^{\circ} \\
(0.21)\end{array}$ \\
\hline \multicolumn{9}{|c|}{ W2: With $500 \mathrm{~g}$} \\
\hline Horizontal & $\begin{array}{c}7.3^{\circ} \\
(0.90)\end{array}$ & $\begin{array}{c}3.0^{\circ} \\
(0.15)\end{array}$ & $\begin{array}{c}7.9^{\circ} \\
(0.94)\end{array}$ & $\begin{array}{c}1.5^{\circ} \\
(0.08)\end{array}$ & $\begin{array}{c}7.0^{\circ} \\
(0.88)\end{array}$ & $\begin{array}{c}2.2^{\circ} \\
(0.15)\end{array}$ & $\begin{array}{c}7.1^{\circ} \\
(0.86)\end{array}$ & $\begin{array}{c}4.7^{\circ} \\
(0.22)\end{array}$ \\
\hline Frontal & $\begin{array}{c}3.4^{\circ} \\
(0.61)\end{array}$ & $\begin{array}{c}2.0^{\circ} \\
(0.20)\end{array}$ & $\begin{array}{c}6.6^{\circ} \\
(0.87)\end{array}$ & $\begin{array}{c}1.9^{\circ} \\
(0.11)\end{array}$ & $\begin{array}{c}4.0^{\circ} \\
(0.68)\end{array}$ & $\begin{array}{c}1.6^{\circ} \\
(0.14)\end{array}$ & $\begin{array}{c}6.0^{\circ} \\
(0.74)\end{array}$ & $\begin{array}{c}4.3^{\circ} \\
(0.35)\end{array}$ \\
\hline Sagittal & $\begin{array}{c}3.7^{\circ} \\
(0.63)\end{array}$ & $\begin{array}{c}1.9^{\circ} \\
(0.19)\end{array}$ & $\begin{array}{c}6.6^{\circ} \\
(0.85)\end{array}$ & $\begin{array}{c}2.8^{\circ} \\
(0.15)\end{array}$ & $\begin{array}{c}4.6^{\circ} \\
(0.73)\end{array}$ & $\begin{array}{c}1.7^{\circ} \\
(0.15)\end{array}$ & $\begin{array}{c}5.8^{\circ} \\
(0.82)\end{array}$ & $\begin{array}{c}1.9^{\circ} \\
(0.13)\end{array}$ \\
\hline \multicolumn{9}{|c|}{ W3: With $1,000 \mathrm{~g}$} \\
\hline Horizontal & $\begin{array}{c}8.1^{\circ} \\
(0.86)\end{array}$ & $\begin{array}{c}6.3^{\circ} \\
(0.33)\end{array}$ & $\begin{array}{c}8.0^{\circ} \\
(0.94)\end{array}$ & $\begin{array}{c}2.5^{\circ} \\
(0.13)\end{array}$ & $\begin{array}{c}7.1^{\circ} \\
(0.84)\end{array}$ & $\begin{array}{c}4.1^{\circ} \\
(0.29)\end{array}$ & $\begin{array}{c}8.6^{\circ} \\
(0.98)\end{array}$ & $\begin{array}{c}1.7^{\circ} \\
(0.08)\end{array}$ \\
\hline Frontal & $\begin{array}{c}3.7^{\circ} \\
(0.65)\end{array}$ & $\begin{array}{c}1.8^{\circ} \\
(0.17)\end{array}$ & $\begin{array}{c}5.6^{\circ} \\
(0.81)\end{array}$ & $\begin{array}{c}1.5^{\circ} \\
(0.10)\end{array}$ & $\begin{array}{c}3.4^{\circ} \\
(0.59)\end{array}$ & $\begin{array}{c}2.5^{\circ} \\
(0.23)\end{array}$ & $\begin{array}{c}4.9^{\circ} \\
(0.73)\end{array}$ & $\begin{array}{c}2.9^{\circ} \\
(0.20)\end{array}$ \\
\hline Sagittal & $\begin{array}{c}3.0^{\circ} \\
(0.55)\end{array}$ & $\begin{array}{c}2.1^{\circ} \\
(0.22)\end{array}$ & $\begin{array}{c}4.4^{\circ} \\
(0.71)\end{array}$ & $\begin{array}{c}2.2^{\circ} \\
(0.17)\end{array}$ & $\begin{array}{c}4.6^{\circ} \\
(0.71)\end{array}$ & $\begin{array}{c}2.1^{\circ} \\
(0.18)\end{array}$ & $\begin{array}{c}3.7^{\circ} \\
(0.65)\end{array}$ & $\begin{array}{l}1.4^{\circ} \\
(0.13)\end{array}$ \\
\hline
\end{tabular}

$[F(2,21)=2.9, p>.08]$ planes. The other interactions were not significant: orientation $\times$ plane $[F(6,189)=1.3$, $p>.25]$, orientation $\times$ forearm condition $[F(6,189)=$ $1.6, p=.14]$, and orientation $\times$ plane $\times$ forearm condition $[F(12,189)=0.5, p>.25]$.

\section{Discussion}

The results concerning the oblique effect are at variance with those predicted, since the magnitude of the oblique effect, although always significant, did not change as a function of the magnitude of gravitational cues (loading conditions W1, W2, and W3). The effect of plane was only partially consistent with our predictions: it changed as a function of forearm condition, but it was absent in the $\mathrm{Wl}$ condition, whereas it was equally present in the W2 and W3 conditions.

\section{GENERAL DISCUSSION}

In this research, we studied the role of the gravitational cues provided by the arm-hand system in the haptic coding of orientation. If the magnitude and variability of these cues during scanning were involved in the elicitation of the oblique effect and the plane effect reported by Gentaz and Hatwell (1995), these effects should be eliminated or attenuated in conditions in which the magnitude and variability of these cues were very low, and they should increase in conditions in which the magnitude and variability of these cues were increased. We tested these hypotheses by asking subjects to reproduce vertical, horizontal, and $+45^{\circ}$ - and $+135^{\circ}$-oblique orientations in different planes and in different forearm conditions of exploration: with reduced levels of $G$ (the supported-forearm condition of Experiment 1 and lightened-forearm condition of Experiment 2), natural (control) condition, and increased levels of G (W2 and W3 loaded-forearm conditions of Experiment 3).

Let us first discuss the role played by the magnitude of gravitational cues in the haptic oblique effect. When these cues were low, the oblique effect was absent or it significantly decreased. The interpretation of an absence of anisotropy is actually equivocal. Observing no oblique effect may mean that the mode of processing was not spatial and was, for instance, based on movement coding, especially on the variation of joint angles. However, no anisotropy may also be observed when, although coding was spatial, the gravitational cues were too poor to generate a difference between vertical and horizontal settings as compared with oblique ones.

When gravitational cues were natural (the unsupportedforearm condition of Experiment 1; the natural control conditions of Experiments 2 and 3), the presence of an oblique effect led to less ambiguous interpretation. As already stated, observing an oblique effect implies that the subject used a mode of processing based on a spatial frame of reference, which is very likely a Cartesian coordinate system. In such a system, vertical and horizontal orientations are parallel to (or superimposed on) the coordinate axes, whereas obliques are not. Coding the vertical and horizontal orientations of the rod requires one therefore to process one dimension only, whereas coding obliques requires one to compute values on the two dimen- 


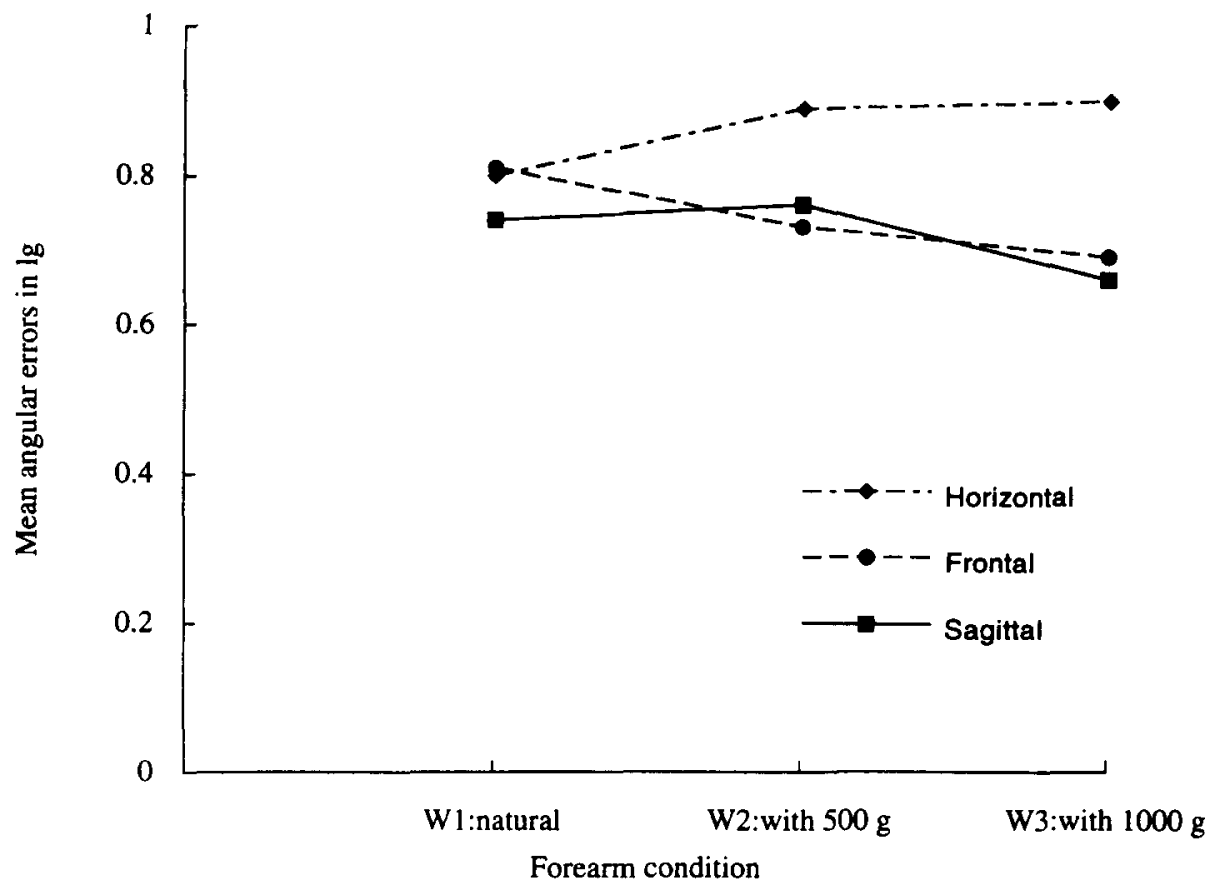

Figure 6. Mean absolute angular errors in $\log$ as a function of forearm condition and plane: Experiment 3.

sions and to integrate these values in order to estimate the actual orientation of the rod.

The oblique effect, which is assumed to result from these differences in the cost of processing, did not appear in the present study when gravitational cues were consistently reduced, and it was observed when these cues were normally available. This suggests that, as predicted, these cues participated in the elicitation of the oblique effect. But how they act in orientation coding is less clear. Our initial assumption was that a decrease of these cues, although increasing errors in all orientations, would affect more severely the accuracy of settings of the vertical (and correlatively horizontal) orientations, because information on verticality is directly given by gravitational cues. This interpretation was partly supported in Experiment 2. In it, increased errors were observed in the vertical-horizontal settings of the lightened-forearm condition, in which gravitational cues were reduced, as compared with the vertical-horizontal settings of the control natural forearm condition, in which gravitational cues were normally available. Because oblique settings were not affected by forearm conditions, the oblique effect was absent in the lightened-forearm condition and was present in the natural control condition. However, an opposite result was observed in Experiment 1 . In it, there was no difference between the vertical-horizontal settings obtained in the supported-forearm condition, in which gravitational cues were reduced, and the unsupportedforearm condition, in which gravitational cues were natural. By contrast, errors increased in the oblique settings of the unsupported-forearm condition, and this increase generated the oblique effect. It is possible that, as stated earlier, this inconsistent result stems from the fact that in Experiment I we tested only the horizontal plane, whereas in Experiment 2 we tested the horizontal, frontal, and sagittal planes. Further research should clarify this point.

When the magnitude of gravitational cues was enhanced (the loaded-forearm conditions W2 and W3 of Experiment 3 ), the oblique effect was present, but, contrary to our hypothesis, it was not increased in these conditions in comparison with the natural control W1 condition.

Taken together, these results showed that the magnitude of gravitational cues acts asymmetrically on the haptic oblique effect. Whereas this effect was attenuated or absent when gravitational cues were decreased, it was not enhanced when these cues were increased. A tentative interpretation of this asymmetry may rely on training effects. In everyday life, the subject's forearm and hand are of ten loaded (with tools, keys, bags, umbrellas, etc.), whereas they are rarely lightened, except when completely immersed in water. Practice with a loaded arm is therefore higher than practice with a lightened arm.

A similar asymmetry of the effects of microgravity and hypergravity (simulated or natural) is found in the literature. For example, as concerns decreased gravity cues, Turvey, Solomon, Burton, Pagano, and Runeson (1992) observed no haptic oblique effect when an oriented rod was held in the hand and wielded. But in this study, gravitational cues were reduced because the subject's forearm rested on a rigid surface while wielding the rod. This condition was similar to our supportedforearm condition of Experiment 1, in which the oblique effect was absent. It would be interesting to test Turvey et al.'s task when the subject's forearm is maintained in 
the air. In a connected field, Fisk et al. (1993) observed that the amplitude of slow movements during the $0 \mathrm{G}$ phase of flight was decreased in the vertical and horizontal planes. Similarly, Bock (1994) found that when the forearm was immersed in water, the proprioceptive position sense in an elbow-angle matching task (in the horizontal plane) was more variable than in normal conditions, and the forearm deviated systematically upward. This set of observations converges to show that reducing or suppressing gravitational cues affects the appreciation of limb position, movement control, and the sensorymotor organization of the arm-hand system.

On the other hand, a number of studies failed to find an effect of hypergravity on perceptual-motor performances. For example, Marchetti and Lederman (1983) found that when the haptic exploration of a standard and a response rod involved the same arm movement (either radial or tangential) in the horizontal plane, the haptic length estimations were not affected when the forearm was weighted with a mass. Similarly, in another condition of Bock's study (1994), the unsupported forearm was loaded with a mass. Results showed that both systematic and variable angle matching errors remained unchanged under simulated hypergravity. Finally, Fisk et al. (1993) found that the ability to reproduce limb movements between practiced end points was not altered during the $1.8 \mathrm{G}$ phase of flight.

Whatever the origin of this asymmetry of effects, our results suggest that, although gravitational cues are involved in haptic orientation coding, the oblique effect is not directly proportional to the amount of these cues. Instead, it may be that the magnitude of these cues plays a role in the selection of the mode of processing and, as a result, in the presence or absence of the oblique effect. A low level of gravitational cues could induce a mode of processing not based on a geocentric frame, but rather on joint-angle coding, which will not elicit an oblique effect. A natural and an increased magnitude of gravitational cues could induce a spatial mode of processing based on a Cartesian coordinate system and would generate the oblique effect. Finally, an intermediate magnitude of gravitational cues could induce a processing based either on movement coding or on a coordinate system, or a mixed processing based on both. These assumptions should be tested in further research.

It is noteworthy that our focus on the role of the Cartesian reference frame in the elicitation of the oblique effect is consistent with the fact that Soechting and Flanders (1992) demonstrated (electrophysiologically or behaviorally) the use of coordinate systems in motor tasks. These authors suggested that it is not coincidental that in all the motor tasks they reviewed, one of the coordinate axes was defined by the gravitational vertical and another by the sagittal horizontal axis. Thus, they proposed "that ultimately there is a common earth-fixed frame of reference used for all motor tasks. As we move in a threedimensional world dominated by gravity forces and by visual horizon, ... one advantage of representing information... in a common spatial frame of reference might be that exchange of information is facilitated" (1992, pp. 186-187). These propositions could reasonably be extended to perceptual processes and to the sensorymotor dialogue in haptics.

Let us examine now the hypothesis that the variability of gravitational cues during scanning also has an effect on the haptic coding of orientation. As was explained in the introduction, variability of these cues was generated by changing the plane in which the task was performed. This variability was low (or nil) in the horizontal plane, because in it, the arm-hand system scanned always in a direction perpendicular to gravity. By contrast, the magnitude of the gravitational cues generated by antigravitational forces varied consistently during scanning in the frontal and sagittal planes as a function of the direction of exploration (upward or downward). We predicted, therefore, that the variability of gravitational cues would enhance the accuracy of settings and that errors would therefore be higher in the horizontal plane than in the frontal and sagittal ones. This prediction was confirmed only in the loaded-forearm (W2 and W3) conditions of Experiment 3 . In all the other conditions tested in Experiments 2 and 3 (the natural control conditions and lightened-forearm condition), the effect of plane was not significant. This means that, although it may be useful, the variability of cues is not the main determinant of haptic coding of orientation. On the other hand, the fact that in the natural conditions, the same oblique effect appeared in the three planes suggests that in the horizontal plane, what is labeled "vertical" (which is actually a projection of the gravitational vertical on the midsagittal horizontal plane) had the same functional properties as did the true gravitational vertical tested in the frontal and sagittal planes.

Of course, in addition to the factors linked to the gravitational cues studied here, the presence of a haptic oblique effect could be partially explained in blindfolded people by visual imagery. Visualization is a process often involved in the haptic spatial functioning of sighted subjects because of the dominant function of vision in human spatial processing (Pick, 1974; for reviews, see Hatwell, 1986, 1990, 1994; Heller, 1991; Millar, 1994). Visual recoding of haptic spatial information has been demonstrated in shape recognition and reconstruction (Worchel, 1951), in the vertical-horizontal illusion (Heller, 1991, 1992; Heller \& Joyner, 1993), in the haptic judgments of orientation (Appelle \& Countryman, 1986; Appelle \& Gravetter, 1985), and so forth. It is therefore likely that visualization participated in the manifestation of the haptic oblique effect in our study, because a strong oblique effect has been systematically found in the visual modality. In order to evaluate the role of visual imagery, haptic orientation coding should be studied in congenitally blind subjects. Lechelt (1988) observed a tactile oblique effect in 5 totally blind adults tested with an electrotactile cutaneous stimulation obtained via the Optacon apparatus (a reading aid for the blind). But only 2 subjects were blind from birth, and the task concerned only passive touch in the horizontal plane. Consequently, 
we are currently testing a group of congenitally blind subjects with our display allowing a measure of the haptic oblique effect in the three planes.

In summary, this study supports Gentaz and Hatwell's (1995) proposals that gravitational cues are involved in the haptic perception of orientation. The oblique effect appeared when the magnitude of these cues was normal or increased, and it was reduced or absent when these cues were reduced. However, increasing and decreasing the values of $G$ level did not have symmetrical effects. Further research should clarify these relations between gravity constraints and haptic coding of orientation by testing other oblique orientations, different from the $+45^{\circ}$ - and $+135^{\circ}$-obliques studied here. For example, examining the effects of changed gravity in the setting of rods whose orientation is varied by steps of $10^{\circ}$ or $15^{\circ}$ would specify the least deviation from the vertical eliciting the oblique effect under each gravity condition. In addition to their theoretical interest, these studies may have practical applications in the manual performance of astronauts during space flight, and more generally in manual tasks in which visual control is not possible.

\section{REFERENCES}

$\mathrm{ABDI}, \mathrm{H}$. (1987). Introduction au traitement statistique des donnés experimentales [Introduction to the statistical analysis of experimental data]. Grenoblc: Presses Universitaires de Grenoble.

Appelle, S. (1972). Perception and discrimination as a function of stimulus orientation: The "oblique effect" in man and animals. Psychological Bulletin. 78. 266-278.

APpelle, S.. \& Colntryman, M. (1986). Eliminating the haptic oblique effect: Influence of scanning incongruity and prior knowledge of the standards. Perception, 15, 365-369.

Appeille. S., \& GravetTFr, F. (1985). Effect of modality-specific experience on visual and haptic judgement of orientation. Perception. 14. 763-773.

Berthinume, F., Robert, M.. Si-Ongie, R., \& Pelletifr, J. (1993). Absence of a gender difference in a haptic version of the water-level task. Bulletin of the Psychonomic Societr: 31. 57-60.

BERTHOZ, A. (1991). Reference frames for the perception and control of movement. In J. Paillard (Ed.), Brain and space (pp. 81-111). New York: Oxford University Press.

Bock, O. (1994). Joint position sense in simulated changed-gravity environments, Aviation, Space, \& Environmental Medicine. 65. 621-626.

Bock, O.. Howard, I. P.. Money, K. E., \& Arnold, K. E. (1992). Accuracy of aimed arm movements in changed gravity. Aviation. Space, \& Environmental Medicine, 63, 994-998.

Bryant, P. (1974). Perception and understanding in voung children. New York: Basic Books.

BRYDEN. M. P. (1977). Measuring handedness with questionnaires. Neuropsychologia, 15, 617-624

CECAI.A, A. J., \& GARNiR, W. R. (1986). Internal frame of reference as a determinant of the oblique effect. Journal of Experimental Psychology: Human Perception \& Performance, 12, 314-323.

Collolo, Y., \& Orliaglet, J. P. (1994). Spatial adaptation of fast pointing movement to inertial pertubation: Evidence for differential adjustment of amplitude and direction. CPC-Current Psicholog! of Cognition. 13.247-265

Coello, Y.. Orlaglet, J. P.. \& Prablanc, C. (1996). Pointing movement in an artificial perturbing inertial field: A prospective paradigm for motor control study. Neuropsichologica, 39, 879-892.

Corbatlis. M. C. \& BtALE. I. L. (1976). The purchology of the left and right. Hillsdale. NJ: Erlbaum

Dick. M.. \& Hochstein. S. (1989). Visual orientation estimation. Pe\%(cption \& Psichophisics. 46. 227-234.
Dietz, V. (1994). Neuronal basis of stance regulation: Interlimb coordination and antigravity receptor function. In S. Swinnen, H. Heuer, J. Massion, \& P. Casaer (Eds.), Interlimb coordination: Neural, dynamical and cognitive constraints (pp. 167-178). New York: Academic Press.

Essock, E. A. (1980). The oblique effect of stimulus identification considered with respect to two classes of oblique effects. Perception, 9, 37-46.

Essock, E. A. (1982). Anisotropies of perceived contrast and detection speed. Vision Research, 22, 1185-1191.

Essock, E. A. (1990). The influence of stimulus length on the oblique effect of contrast sensitivity. Vision Research, 30, 1243-1246.

Fisk, J., LACkNer, J. R., \& DiZio, P. (1993). Gravitoinertial force level influences arm movement control. Journal of Neurophysiology, 69 , 504-511.

Gentaz, E., \& Hatwell, Y. (1995). The haptic "oblique effect" in children's and adults' perception of orientation. Perception, 24, 631-646.

Goodwin, G. M., McCloskey, D. I., \& Matthews, P. B. C. (1972). The contribution of muscle afferents to kinesthesia shown by vibration induced illusions of movements and by the effects of paralyzing joint afferents. Brain, 95, 705-748.

Harris, P., Le Tendre, J., \& Bishop, A. ( 1974). The young child's discrimination of obliques. Perception, 3, 261-265.

Hatwell, Y. (1986). Toucher l'espace: La main et la perception tactile de l'espace [Touching space: The hand and the haptic perception of space]. Lille: Presses Universitaires de Lille.

HatWELL, Y. (1990). Spatial perception by eye and hand: Comparison and intermodal integration. In C. Bard, M. Fleury, \& L. Hay (Eds.), Development of eye-hand coordination across life-span (pp. 99132). Columbia: University of South Carolina Press.

HaTWELL, Y. (1994). Transferts intermodaux et intégration intermodale [Intermodal transfer and intermodal integration]. In M. Richelle, J. Requin, \& M. Robert (Eds.), Traité de Psychologie Expérimentale [Handbook of experimental psychology] (Vol. 1, pp. 543-584). Paris: Presses Universitaires de France.

HEELEY, D. W., \& TimmEY, B. (1988). Meridional anisotropies of orientation discrimination for sine wave gratings. Vision Research, 28 , 337-344.

Heller, M. A. (1991). Haptic perception in blind people. In M. A. Heller \& W. Schiff (Eds.), The psychology of touch (pp. 239-261). Hillsdale, NJ: Erlbaum.

Heller, M. A. (1992). The effect of orientation on tactual braille recognition: Optimal touching positions. Perception \& Psychophysics, 51, 549-556.

Heller, M. A., \& Joyner, T. D. (1993). Mechanisms in the haptic horizontal-vertical illusion: Evidence from sighted and blind subjects. Perception \& Psychophysics, 53, 422-428.

Howard. I. P. (1982). Human visual orientation. New York: Wiley. JENKINS, B. (1985). Orientational anisotropy in the human visual system. Perception \& Psychophysics, 37, 125-134.

LASAGA. M. I., \& GARNER. W. R. (1983). Effect of line orientation on various information-processing tasks. Journal of Experimental Psuchology: Human Perception \& Performance, 9, 21 5-225.

LECHELT, E. C. (1988). Spatial asymmetries in tactile discrimination of line orientation: A comparison of the sighted, visually impaired, and blind. Perception, 17, 579-585.

LFCHELT, E. C. (1992). Tactual spatial anisotropy with static stimulation. Bulletin of the Psichonomic Societl, 30, 140-142.

Lechel., E. C., Eliuk, J., \& TAnne, G. (1976). Perceptual orientational asymmetries: A comparison of visual and haptic space. Perception \& Psichophrsics, 20, 463-469.

LeCheLt, E. C.. \& Verenka. A. (1980). Spatial anisotropy in intramodal and cross-modal judgements of stimulus orientations: The stability of the oblique effect. Perception, 9, 581-589.

LII.IIEFors, H. W. (1967). On the Kolmogorov-Smirnov test for normality with mean and variance unknown. Journal of the American Statistical Association, 64, 387-389

L.ovci, G. M., \& TuCK, J. P. (1991). Comparison of contrast sensitivity functions across three orientations: Implications for theory and testing. Perception. 20. 373-380.

M ARe hetil. F. M.. \& Lederman, S. J. (1983). The haptic radial 
tangential effect: Two tests of Wong's "moment-of-inertia" hypothesis. Bulletin of the Psychonomic Society, 21, 43-46.

MARTINEZ, F. (1971). Comparison of two types of tactile exploration in a task of mirror-image recognition. Psychonomic Science, 22, 124-125.

Millar, S. (1994). Understanding and representing space: Theory and evidence from studies with blind and sighted children. Oxford: Oxford University Press, Clarendon Press.

Paillard, J. (1971). Les déterminants moteurs de l'organisation spatiale [Motor determinants of spatial organization]. Cahiers de Psychologie, 14, 261-316.

Paillard, J. (1974). Le traitement des informations spatiales [The processing of spatial information]. In J. Bresson, P. Chombart de Lauwe, M. Cullen, G. T. Guilbaud, J. Paillard, E. De Renzi, \& E. Vurpillot (Eds.), De l'espace corporel à l'espace écologique [From corporal space to ecological space] (pp. 7-54). Paris: Presses Universitaires de France.

Paillard, J. (1991). Brain and space. New York: Oxford University Press.

PICK, H. L. (1974). Visual coding of non-visual spatial information. In R. B. MacLead \& H. L. Pick (Eds.), Perception (pp. 153-165). Ithaca, NY: Cornell University Press.

ROBERT, M., \& OHLManN, T. (1994). Water-level representation by men and women as a function of rod-and-frame proficiency and visual and postural information. Perception, 23, 1321-1333.

Rock, I. (1983). The logic of perception. Cambridge, MA: MIT Press.

RoLL, J.-P. (1994). Sensibilités cutanées et musculaires [Cutaneous and muscular sensibilities]. In M. Richelle, J. Requin, \& M. Robert (Eds.), Traité de Psychologie Expérimentale [Handbook of experimental psychology] (Vol. 1, pp. 483-542). Paris: Presses Universitaires de France.

Roll, J.-P., Vedel, J.-P., Gilhodes, J.-C., \& Ribot, R. (1986). Proprioceptive sensory coding of motor activities in man. In S. Ron, R. Schmid, \& M. Jeannerod (Eds.), Sensorimotor plasticity (pp. 283304). Paris: Inserm.

SaARINEN, J., \& LEVI, D. (1995). Orientation anisotropy in vernier acuity. Vision Research, 35, 2449-2461.
SoEChting, J. F., \& Flanders, M. (1992). Moving in three-dimensional space: Frames of reference, vectors, and coordinate systems. Annual Review of Neuroscience, 15, 167-191.

Soechting, J. F., \& Ross, B. (1984). Psychophysical determination of coordinate representation of human arm orientation. Neuroscience, 13, 595-604.

Turvey, M. T., Solomon, H. Y., Burton, G., Pagano, C. C., \& RuneSON, S. (1992). Role of the inertia tensor in perceiving object orientation by dynamic touch. Journal of Experimental Psychology: Human Perception \& Performance, 3, 714-727.

Vogels, R., \& Orban, G. A. (1985). The effect of practice on the oblique effect in line orientation judgements. Vision Research. 25, 1679-1687.

Voyer, D., Voyer, S., \& Bryden, M. P. (1995). Magnitude of sex differences in spatial abilities: A meta-analysis and consideration of critical variables. Psychological Bulletin, 117, 250-270.

WALKER, J. T. (1972). Tactual field dependence. Psychonomic Science, 26, 311-313.

Watt, D. G. D., Money, K. E., Bondar, R. L., Thirsk, R. B., GarNEAU, M., \& Scully-Power, P. (1985). Canadian medical experiments on shuttle flight 41-G. Canadian Aeronautics Space Journal. 31, 215-226.

WoNG, T. S. (1977). Dynamic properties of radial and tangential movements as determinants of the haptic horizontal-vertical illusion with an L figure. Journal of Experimental Psychology: Human Perception \& Performance, 3, 151-164.

WORCHEL, P. (1951). Space perception and orientation in the blind. Psychological Monographs, 65 (15).

Worringham, C. J., Stelmach, G. E., \& Martin, Z. E. ( 1987 ). Limb segment inclination sense in proprioception. Experimental Brain Research, 66, 653-658.

(Manuscript received April 11, 1995; revision accepted for publication January $31,1996$. 